\title{
Studi Deskriptif Kelengkapan Dokumen Rekam Medis
}

\section{Descriptive Study The Completeness Of Medical Record Documents}

\author{
Ika Setya Purwanti1) \\ Diah Prihatiningsih ${ }^{2}$ \\ Ni Luh Putu Devhy) \\ 1,3) Program Studi RMIK, STIKes Wira Medika Bali \\ 2) Program Studi Keperawatan, STIKes Wira Medika Bali \\ Email : davyathaa@gmail.com
}

\begin{abstract}
Medical records are files that contain records and patient identify documents, the results of examination treatments, action, and services that have been provided. The completeness of filling in the medical record file can make it easier for other health workers to provide patient action or treatment, and can be used as a useful source of information for hospital management in determining the evaluation and development of health services. The purpose of this research was to study the complete picture of medical record documents at Sanjiwani General Hospital, Gianyar. This research is a quantitative study using the checklist in accordance with Permenkes RI No. 269/Menkes/Per/III/2008. The method used in this study was observation using cross sectional and restrospective data collection. The results of this study indicate that the completeness of the medical record from the patients identity, the identity of the doctor, the identity of the nurse shows a completeness of $100 \%$ and the completeness of the information was $64,1 \%$. Analysis of data from this research used descriptive methods. So that it is expcted from the results of this study to maintain the awareness and discipline of the officers responsible for filling out medical record in accordance with predetermined procedures.
\end{abstract}

Keywords : medical records, complete documents, patient documents

\begin{abstract}
Abstrak
Rekam medis adalah berkas yang berisi catatan dan dokumen identitas pasien, hasil pemeriksaan, pengobatan, tindakan dan pelayanan yang telah diberikan. Kelengkapan pengisian berkas rekam medis dapat memudahkan tenaga kesehatan lain dalam memberikan tindakan atau pengobatan pasien, dan dapat dijadikan sebagai sumber informasi yang berguna bagi manajemen rumah sakit dalam menentukan evaluasi dan pengembangan pelayanan kesehatan. Tujuan penelitian ini adalah untuk mengetahui gambaran kelengkapan rekam medis di RSUD Sanjiwani, Gianyar. Penelitian ini merupakan penelitian kuantitatif dengan menggunakan Check list sesuai dengan Permenkes RI No. 269/Menkes/Per/III/2008. Metode yang digunakan dalam penelitian ini adalah observasi dengan pendekatan cross sectional dan pengambilan datanya secara retrospektif. Hasil dari penelitian ini menunjukkan bahwa kelengkapan rekam medis dari kelengkapan identitas pasien, kelengkapan identitas dokter, kelengkapan identitas perawat menunjukkan kelengkapan rekam medis sebesar 100\% sedangkan kelengkapan inform concern sebanyak 64,1\%. Analisis data dalam penelitian ini menggunakan metode deskriptif. Dari hasil penelitian ini diharapkan agar rumah sakit dapat mempertahankan kesadaran dan kedisiplinan petugas yang bertanggung jawab dalam pengisian rekam medis sehingga sesuai dengan prosedur yang telah ditetapkan.
\end{abstract}

Kata Kunci : kelengkapan rekam medis, studi deskriptif 


\section{PENDAHULUAN}

Rumah Sakit merupakan lembaga kesehatan yang kompleks yang memerlukan suatu sistem informasi yang baik dalam menjalankan aktivitasnya. Rekam medis merupakan keharusan yang penting bagi data pasien untuk diagnosis dan terapi, namun dalam perkembangannya rekam medis dapat digunakan untuk kepentingan pendidikan dan penelitian serta untuk masalah hukum (Sabarguna, 2007). Permenkes No: 269/Menkes / Per/III/2008 rekam medis adalah berkas yang berisi catatan dan dokumen identitas pasien, hasil pemeriksaan, pengobatan, tindakan dan pelayanan yang telah diberikan. Kelengkapan pengisian berkas rekam medis dapat memudahkan tenaga kesehatan lain dalam memberikan tindakan atau pengobatan pasien, dan dapat dijadikan sebagai sumber informasi yang berguna bagi manajemen rumah sakit dalam menentukan evaluasi dan pengembangan pelayanan kesehatan (Hatta, 2012). Masalah yang sering timbul dalam pengisian rekam medis adalah dalam proses pengisiannya tidak lengkap, penulisan dokter yang kurang spesifik mengenai diagnosa. Keadaan ini akan mengakibatkan dampak bagi intern rumah sakit dan ekstern rumah sakit, karena hasil pengolahan data menjadi dasar pembuatan laporan intern rumah sakit dan laporan ekstren rumah sakit. Laporan ini berkaitan dengan penyusunan berbagai perencanaan rumah sakit, pengambilan keputusan oleh pimpinan khususnya evaluasi pelayanan yang telah diberikan yang diharapkan hasil evaluasinya akan menjadi lebih baik (Givana, 2012). Ketidaklengkapan rekam medis menjadi salah satu masalah karena rekam medis merupakan catatan data yang dapat memberikan informasi mengenai tindakan pada pasien. Berkas rekam medis bertujuan untuk menunjang tercapainya tertib administrasi dalam upaya peningkatan mutu pelayanan kesehatan di rumah sakit, maka pengisian rekam medis haruslah diisi dengan lengkap sehingga dapat menghasilkan informasi yang akurat (Budi, 2011).

Rekam medis dikatakan lengkap apabila memenuhi indikator dalam kelengkapan pengisian, keakuratan, tepat waktu, sehingga dapat dipercaya dan lengkap maka perlu dilakukan tinjauan kelengkapannya. Apabila rekam medis belum lengkap setelah pasien selesai pelayanan atau perawatan dengan batas waktu pelengkapan rekam medis $2 \times 24$ jam dapat dikategorikan sebagai IMR (Incomplete Medical Record) sedangkan dokumen rekam medis yang belum lengkap setelah melebihi masa pelengkapan dari masing-masing unit pelayanan dengan batas waktu pelengkapan rekam medis lebih dari 14 hari maka rekam medis dikategorikan DMR (Delinquent Medical Record, (Shofari, B. 2002).

Berdasarkan laporan Triwulan I tahun 2015 disebutkan bahwa sesuai dengan misi Rumah Sakit Umum Daerah (RSUD) Sanjiwani Gianyar untuk dapat memberikan pelayanan bermutu dengan mengutamakan keselamatan pasien, untuk itu RSUD Sanjiwani Gianyar melakukan kegiatan peningkatan mutu dan keselamatan pasien yang sesuai dengan standar akreditasi KARS versi 2012. Kegiatan ini di lakukan di setiap unit kerja/instalasi terkait untuk mengukur kinerja pelayanan RS dan sebagai manajemen kontrol untuk mendukung pengambilan keputusan. Salah satu indikator mutu rumah sakit di area klinik adalah kelengkapan pengisian rekam medis 24 jam sejak setelah selesai pasien rawat inap (KARS, 2012). Pada laporan triwulan I 2015 belum terdapat angka ketidaklengkapan pengisian rekam medis 24 jam sejak setelah selesai pasien rawat inap.

Pada laporan triwulan III tahun 2015 salah satu indikator mutu di rumah sakit yaitu kelengkapan rekam medis, didapatkan angka target ketidaklengkapannya adalah sebesar 5\%. Pencapaian di bulan juli, presentasi 
ketidaklengkapannya adalah $54,6 \%$ pada bulan Agustus 17,78\% pada bulan September $0 \%$. Sehingga rata rata ketidaklengkapan pengisian rekam medis 24 jam sejak setelah selesai pasien rawat inap adalah 24,13\%.

Mengingat pentingnya rekam medis dalam menciptakan informasi yang berkesinambungan, maka penulis tertarik untuk meneliti tentang gambaran kelengkapan dokumen rekam medis di RSUD Sanjiwani, Gianyar tahun 2017.

\section{Metode}

Analisis kuantitatif menggunakan Check list sesuai dengan Permenkes RI No. 269/Menkes/Per/III/2008 seperti identitas pasien, tanggal dan waktu, hasil anamnesis, hasil pemeriksaan fisik dan medik, odontogram, diagnosis, rencana penatalaksanaan, pengobatan dan atau tindakan, nama dan tanda tangan dokter, perbaikan kesalahan dibubuhi tanda tangan tanpa dihapus.

Jenis penelitian yang digunakan adalah penelitian deskriptif yaitu menggambarkan hasil penelitian sesuai keadaan yang sebenarnya. Metode yang di gunakan dalam penelitian ini adalah observasi dengan pendekatan cross sectional dan pengambilan datanya secara retrospektif.

\section{Hasil dan Pembahasan}

Hasil penelitian kelengkapan rekam medis yang dilakukan di RSUD Sanjiwani Gianyar terdiri dari beberapa kelengkapan, diantaranya kelengkapan identitas pasien, kelengkapan identitas dokter, kelengkapan identitas perawat, kelengkapan inform concert, kelengkapan anesthesia, kelengkapan resume, kelengkapan CD $\mathrm{X}$, keterbacaan, penataan, dan penutupan.

Tabel 1. Kelengkapan Rekam Medis

\begin{tabular}{lcccc}
\hline \multicolumn{1}{c}{ Kelengkapan Rekam Medis } & \multicolumn{2}{c}{ Frekuensi } & \multicolumn{2}{c}{ Persentase (\%) } \\
\hline & Lengkap & Tidak Lengkap & Lengkap & Tidak \\
Kelengkap \\
Kelengkapan Identitas Pasien & 103 & 0 & 100 & 0 \\
Kelengkapan Identitas Perawat & 103 & 0 & 100 & 0 \\
Kelengkapan Inform Concernt & 66 & 0 & 100 & 0 \\
Kelengkapan Anasthesi & 27 & 37 & 64,1 & 35,9 \\
Kelengkapan Resume & 103 & 76 & 26,2 & 73,8 \\
Kelengkapan CD X & 100 & 3 & 100 & 0 \\
Keterbacaan Rekam Medis & 103 & 0 & 100 & 2,9 \\
Penataan Formulir Rekam Medis & 103 & 0 & 100 & 0 \\
Penutupan Formulir Rekam & 103 & 0 & 100 & 0 \\
Medis & & & & \\
\hline
\end{tabular}

Dari hasil penelitian menunjukkan bahwa rekam medis yang ada di RSUD Sanjiwani mempunyai kelengkapan yang baik. Identitas pasien mempunyai kelengkapan 100\%, identitas dokter mempunyai kelangkapan $100 \%$, identitas perawat juga memiliki kelengkapan $100 \%$.

Hal ini sudah sesuai dengan UU RI No. 29 tahun 2004 pasal 46 ayat 3 :"Setiap catatan rekam medis harus dibubuhi nama, waktu, dan tanda tangan petugas yang memberikan pelayanan atau tindakan". Menurut Departemen Kesehatan Republik Indonesia tahun 2006, dikatakan lengkap apabila sebesar $100 \%$

Dari hasil penelitian dapat diketahui bahwa kelengkapan penulisan inform concern sebesar 64,1\%. Kelengkapan anasthesi sebesar 26,2\%. Kelengkapan resume sebesar $100 \%$ dan juga kelengkapan 
CD X sebesar 97,1\%. Rekam medis yang teliti adalah dokumen dari rawat inap dan rawat jalan, sehingga ada beberapa hal tidak lengkap.

Dalam melakukan analisis ini laporan yang dilihat meliputi kelengkapan seluruh item pada setiap formulir yang dianggap penting. Laporan yang penting dalam berkas rekam medis sangat berguna untuk mengetahui kesimpulan pada akhir perawatan, keterangan diagnose akhir, tindakan yang dilakukan oleh dokter dan tenaga kesehatan lain dalam merawat pasien. Dokumen rekam medis diharapkan memuat informasi yang akurat, lengkap, dan dapat dipercaya.

Dokumen rekam medis yang diteliti dari segi keterbacaan laporan, mendapatkan hasil bahwa 103 buah atau $100 \%$ dokumen dapat terbaca laporannya. Penataan laporan rekam medis juga sudah sesuai dengan aturan yang ada. Semua 103 dokumen atau $100 \%$ mempunyai penataan yang baik. Untuk penutupan laporan juga seperti itu, semua laporan rekam medis yang diteliti sebanyak 103 buah mempunyai penutupan laporan.

Kelengkapan pelaporan penting dilaksanakan karena dokumen rekam medis dapat digunakan sebagai alat pemeliharaan kesehatan dan pengobatan pasien yang baik, alat bukti dalam penegakan hukum, keperluan pendidikan dan penelitian, dasar membayar biaya pelayanan kesehatan.

Dari keseluruhan hasil penelitian yang telah dilakukan di unit kerja rekam medis RSUD Sanjiwani menunjukkan bahwa dokumen rekam medisnya sudah lengkap dan baik dalam pengisiannya.

Dokumen rekam medis di RSUD Sanjiwani Gianyar tentang review otentifikasi menunjukkan 100 persen ada identitas nama dokter beserta tanda tangannya. Menurut Permenkes RI No. 269 tahun 2008 tentang tata cara penyelenggaraan rekam medis Bab III pasal 5 ayat 4 menyebutkan bahwa setiap pencatatan ke dalam rekam medis harus di bubuhin nama, waktu dan tanda tangan dokter, dokter gigi atau tenaga kesehatan Copyright @2020 Jurnal Rekam Medis dan Informasi Kesehatan e-ISSN 2622-7614 tertentu yang memberikan pelayanan lesehatan secara langsung. Menurut UU RI No. 29 tahun 2004 pasal 46 ayat 3 : "Setiap catatan rekam medis harus dibubuhi nama, waktu, dan tanda tangan petugas yang memberikan pelayanan atau tindakan".

\section{Simpulan dan Saran}

Kesimpulan yang dapat diambil dari penelitian ini adalah kelengkapan rekam medis dilihat dari identitas pasien, identitas dokter, identitas perawat menunjukkan kelengkapan sebesar $100 \%$ dan Kelengkapan inform concern sebanyak $64,1 \%$.

Saran yang dapat diberikan adalah perlu mempertahankan kesadaran dan kedisiplinan petugas yang bertanggung jawab dalam pengisian rekam medis agar sesuai dengan prosedur yang telah ditetapkan sehingga kelengkapan rekam medis yang sudah tercapai dapat terus dipertahankan.

\section{Daftar Pustaka}

Givana, Frenti, 2012, Analisis Sistem Pengelolaan Rekam Medis Rawat Inap Rumah Sakit Umum Daerah Kota Semaran\%o, Jurnal Kesehatan Masyarakat, Volume 1, Nomor 2, Tahun 2012, Halaman 48 - 61.

Hatta, Gemala R., (ed.) 2012, Pedoman Manajemen Informasi Kesehatan di Sarana Pelayanan Kesehatan: Revisi Buku Petunjuk Teknis Penyelenggaraan Rekam MedisjMedical Record Rumah Sakit (1991) dan Pedoman Pengelolaan Rekam Medis Rumah Sakit di Indonesia (1994, 1997), edk 2, Penerbit Universitas Indonesia, UI- Press, Jakarta.

KARS, 2012. Instrumen Akreditasi RS Standar Akreditasi Versi 2012. Jakarta

Peraturan Menteri Kesehatan (PERMENKES) Nomor 269/MENKES/PER/III/2008 tentang Rekam Medis. 
